\title{
En una tierra inmensa y sin clérigos. La fundación del seminario del Tucumán, 1587-1611
}

\author{
In a Vast Land without a Single Priest. \\ The Founding of the Tucuman Seminary, 1587-1611
}

\author{
Leticia Pérez Puente \\ Instituto de Investigaciones sobre la Universidad y la Educación \\ Universidad Nacional Autónoma de México \\ lpp@unam.mx
}

\section{Resumen}

En este trabajo se estudia la creación del seminario conciliar de la diócesis del Tucumán. Un colegio muy distinto a los ordenados en el concilio de Trento, tanto por sus características, como porque su fundación formal tuvo por objetivo que la Compañía de Jesús se arraigara en el territorio tucumano y se hiciera cargo de la evangelización. Se trata de un ejemplo de cómo los mandatos del Concilio de Trento debieron modificarse al implantarse en Indias, pues, al igual que cualquier otra norma, los decretos canónicos tuvieron que adaptarse para responder a las necesidades de cada una de las diócesis, a las características de la tierra y a la forma en que en ella se organizaban los poderes.

Palabras clave: Seminario conciliar; formación del clero; Tucumán colonial; Santiago del Estero; Compañía de Jesús.

\section{Abstract}

This paper studies the creation of the Conciliar Seminary of the Diocese of Tucuman. This college was very different from those ordered by the Council of Trent, both because of its characteristics, and also because of its formal founding was intended to insert the Society of Jesus in Tucuman territory and undertake evangelization. It is an example of how the mandates of the Council of Trent had to be modified when they were implemented in the Indies, since, like any other norm, canonical decrees were forced to adapt to the requirements of each diocese, the characteristics of the land and the way the powers were organized.

Key words: Conciliar Seminary; formation of the clergy, Colonial Tucuman; Santiago del Estero; Society of Jesus.

Fecha de recepción: 30 de mayo de 2012 Fecha de aceptación: 28 de octubre de 2013 


\title{
En una tierra inmensa y sin clérigos. La fundación del seminario del Tucumán, 1587-1611*
}

\author{
Leticia Pérez Puente
}

Como la tierra es tan dilatada y tan yerma e inculta, $y$ son tantas y tan bravas las fieras que la habitan, y tantos los monstruos y vicios que la estragan y afean, hay mies para todos...

Rebadeneyra (1595, p. 70).

T a formación del clero y su reforma moral fueron preocupaciones cenLtrales del Concilio de Trento, a lo cual obedecieron, entre otras muchas disposiciones, las contenidas en la sesión xxiII, donde se ordenó la creación de seminarios conciliares (El Sacrosanto, 1785, ses. 23, cap. XVIII). De acuerdo con el mandato tridentino, esos colegios debían establecerse en todas las diócesis para educar, alimentar e instruir a quienes tendrían a su cargo la cura de almas. A diferencia de otras instituciones donde también se podía formar a la clerecía, el rasgo distintivo de estos colegios fue que debían estar bajo la exclusiva dirección y gobierno del obispo, y ser mantenidos de las rentas eclesiásticas de las diócesis; es decir, con una parte de lo que montara la mesa episcopal y capitular, las dignidades, personados, oficios y beneficios, aun de regulares o de derecho de patronato. También se debían imponer cargas a las abadías, prioratos, hospitales y fábricas de las iglesias, confraternidades y monasterios.

Al otorgar al obispo la capacidad para imponer pensiones económicas sobre las rentas de todos los cuerpos y comunidades eclesiásticas, el concilio tuvo por objetivo afirmar la jurisdicción del prelado, así como el modelo diocesano de Iglesia, esto es, centrada en el obispo, para cuyo crecimiento, en

* Agradezco a la doctora Ana Inés Punta el haberme prestado las actas del Cabildo de la catedral de Santiago del Estero, editadas por Silvia Palomeque. Este trabajo contó con el respaldo de la Dirección General de Asuntos del Personal Académico de la UNAM, a través de su Programa de Apoyo a Proyectos de Investigación e Innovación Tecnológica PAPIIT-IN 401412 .

Secuencia, ISSN 0186-0348, núm. 94 | enero-abril de 2016 | pp. 6-38

\section{()ㅜ(1) $\$$}


adelante, todos estarían obligados a contribuir. Además, gracias a la dirección y elección de los jóvenes que vivirían y se formarían en los seminarios, el obispo podría establecer mayores lazos con la comunidad y el clero. De esa forma, al igual que en el conjunto de los decretos conciliares, en el relativo a los seminarios, el concilio ecuménico tuvo por finalidad el restablecimiento de la jerarquía eclesiástica y la primitiva autoridad episcopal.

Debido a ello, estas instituciones fueron particularmente atractivas para muchos obispos americanos, sobre todo porque les permitirían crear un cuerpo de ministros estrechamente vinculado a ellos y contar con personal capacitado para la prédica del evangelio. En ese sentido, los frailes, quienes hasta entonces se desempeñaban como curas de almas al margen de la autoridad de los prelados, podrían ser sustituidos por clérigos seculares en la conducción de las parroquias indígenas.

Constancia de ese interés del episcopado, es cómo, en los últimos 30 años del siglo XVI, se erigieron seminarios en 37\% de las diócesis americanas: Quito, Guadalajara, Santa Fe, La Plata, Santiago de Chile, La Imperial, Los Reyes, Cuzco, Guatemala y Santiago del Estero, en el Tucumán. ${ }^{1}$

Como en el caso de otros seminarios, la historiografía eclesiástica que trató sobre el del Tucumán, se preocupó por hacer remontar su fundación a épocas tempranas. Así, antes del seminario dado para su administración a la Compañía de Jesús en 1611, se habló de la existencia de un primer colegio creado en 1587 por el obispo Fray Francisco de Victoria, al que se supone habría seguido uno más, erigido en 1597 por Trejo y Sanabria en la Villa de Nueva Madrid de las Juntas. ${ }^{2}$

El ánimo de la historiografía por apuntar la existencia de esas primeras fundaciones se debió, por un lado, a su interés por demostrar la temprana intención de los obispos de acatar el mandato tridentino y, por otro lado, a que era de esperarse que el colegio se hubiera creado en el siglo XVI, debido a la absoluta falta de clérigos y las extraordinarias dimensiones de la diócesis. Al lado de esas preocupaciones, la idea preconcebida de cómo debía ser un seminario y cuáles sus objetivos impidió a aquella historiografía, y a otra más reciente, percatarse de la necesaria transformación que debió sufrir el modelo tridentino al implantarse en Indias. ${ }^{3}$

${ }^{1}$ Actualmente preparo un estudio más amplio sobre la fundación de los seminarios en Indias.

${ }^{2}$ Sobre las vicisitudes de esta institución hasta 1879 véase Altamira (1943).

${ }^{3}$ De lectura obligada para este tema es el libro de Vergara (2003, pp. 194-196). Se trata de un análisis general de esta institución en Indias del siglo XVI al XVIII donde, por lo mismo,

\section{()ㅜ(1) $\$$}


Precisamente, es objetivo de este texto insistir en cómo, al igual que la mayoría de los mandatos dispuestos en Trento, el relativo a los seminarios no creó instituciones uniformes, acordes con el mandato canónico. Estas debieron adaptarse y modificarse, para así responder a las necesidades de cada una de las diócesis, a las características de la tierra, a las decisiones tomadas por las autoridades y a la forma en que se organizaban los poderes.

Muy lejos de las disposiciones del concilio ecuménico, y aun de las pretensiones de muchos prelados indianos, el seminario de Santa Catarina Mártir no fue un colegio gobernado en exclusiva por el obispo, ni se creó con la intención de formar a los clérigos necesarios para atender a las tareas evangelizadoras y, finalmente, tampoco sirvió, como esperaba Trento, para fortalecer la jurisdicción episcopal.

Según veremos, debido al tamaño de la diócesis, la falta de apoyo para el crecimiento de las órdenes mendicantes y el lento desarrollo de la Iglesia diocesana, el seminario sólo se pudo crear en 1606, cuando el gobierno diocesano había alcanzado ya cierta estabilidad política y económica. Con todo, cinco años después se le instituyó jurídicamente con el objeto de favorecer un modelo institucional distinto de formación. Como podremos constatar, la fundación formal del colegio hecha en 1611 tuvo por objetivo arraigar a la Compañía de Jesús en el territorio tucumano y, a consecuencia de ello, la institución perdió las características que, de acuerdo con Trento, debían distinguir a un seminario conciliar.

\section{UNA IGLESIA EN CONSTRUCCIÓN}

Al describir la gobernación del Tucumán, Juan de Matienzo (1910) anotó que tenía por límites "la cordillera de Chile por la una parte de poniente, y por la de levante, el Río mismo de la Plata, y por la parte del norte, el río del Pilcomayo y, por la del sur, el río Salado” (p. 189). ${ }^{4}$

no se atiende a cómo los seminarios adquirieron características propias según las particularidades de las diócesis.

${ }^{4}$ El primer asentamiento español en el actual territorio tucumano fue fundado en 1550 por Juan Núñez de Prado. La población fue luego trasladada dos veces hasta establecerse definitivamente a orillas del Río del Estero en 1553, con el nombre de Santiago del Estero, fuera de los límites de la jurisdicción chilena, de la que originalmente dependía. En agosto de 1563, al delimitarse el territorio de la Audiencia de Charcas, la gobernación de Tucumán, Juries y Diaguitas, junto con las tierras y zonas de poblamiento de Andrés Manso y Ñuflo Chaves, quedaron sujetas a ella. Charcas, 418, L. 1, f. 66. Archivo General de Indias (en adelante AGI), Sevilla.

\section{(ㅇ)(1) $\$$}


Lo así señalado era una región de más de 700000 kilómetros cuadrados -esto es, una superficie mayor al actual territorio español-, donde hacia 1563 había tan sólo un clérigo encargado de la administración de los sacramentos (Altamira, 1943, pp. 13-14) (véase mapa 1).

El obispado fue erigido en 1570, como sufragáneo de Lima, en la ciudad de Santiago del Estero, y su primer prelado fue el dominico portugués fray Francisco de Victoria. Nombrado en 1578, tomó posesión de su sede tres años después, a fines de 1581. A él habían precedido en la mitra tucumana Francisco de Beaumont, ${ }^{5}$ fray Jerónimo de Albornoz, ${ }^{6}$ y fray Jerónimo de Villacarrillo, ${ }^{7}$ pero este último renunció a la sede y los otros dos murieron antes de poder tomar posesión. Así, los años del gobierno episcopal de Francisco de Victoria (1581-1590), son los de la formación de la Iglesia del Tucumán; un periodo caracterizado por la inestabilidad de la catedral y la falta de clérigos. Motivo, este último, por el cual se atribuye a ese obispo la creación del primer seminario de la diócesis, así como porque fue uno de los asistentes al tercer concilio limeño (1582-1583), donde se legisló sobre cómo estos establecimientos debían fundarse y sostenerse en el Perú. ${ }^{8}$ Si bien ese concilio conminó a todos los obispos a la creación de seminarios, "superando toda clase de impedimentos", los enfrentados en el Tucumán no eran sencillos de vencer.

En 1584, a tres años de haber llegado a su sede, el obispo Victoria pidió al rey le aceptara la dejación del obispado, por el poco fruto que en él podía hacerse. Según explicó, debido a la pobreza de la tierra, no había quién quisiera tomar el estado eclesiástico y, así, sólo contaba con cinco clérigos para atender un distrito donde había más de 100000 almas. ${ }^{9}$ Además, señaló el obispo, el diezmo no era suficiente para poder sustentarse, y si bien el rey le había hecho merced de 500000 maravedíes, no había de dónde cobrarles. Otro motivo para esa falta de clérigos era, según Victoria, la persecución de que habían sido objeto los eclesiásticos durante el gobierno de Hernando de Lerma. "Fuera de los que prendió el gobernador no quedaron más de dos

${ }^{5}$ Bula de Pío V por la que provee obispo de Tucumán a Francisco de Beaumont. 14 de mayo de 1570. Bulas y Breves, 56. AGI, Sevilla.

${ }^{6}$ Recibo de las bulas del obispado de Tucumán. 17 de marzo de 1571. Charcas, 418, L. 1, f. 232v. AgI, Sevilla.

${ }^{7}$ Cédula al Cabildo de Tucumán para que se permita gobernar y administrar el obispado a fray Jerónimo de Villacarrillo. 6 de abril de 1576. Buenos Aires, 5, L. 1, fs. 3-4. AGI, Sevilla.

${ }^{8}$ Las actas del concilio en Carrillo (2007, vol. 2, cap. 44, acción segunda).

${ }_{9}$ Carta del obispo fray Francisco de Victoria, 6 de abril de 1584 (citada en Pastells, 1912, vol. I, p. 25).

\section{(ㄷ)(1) $(3$}


Mapa 1. Gobernación del Tucumán

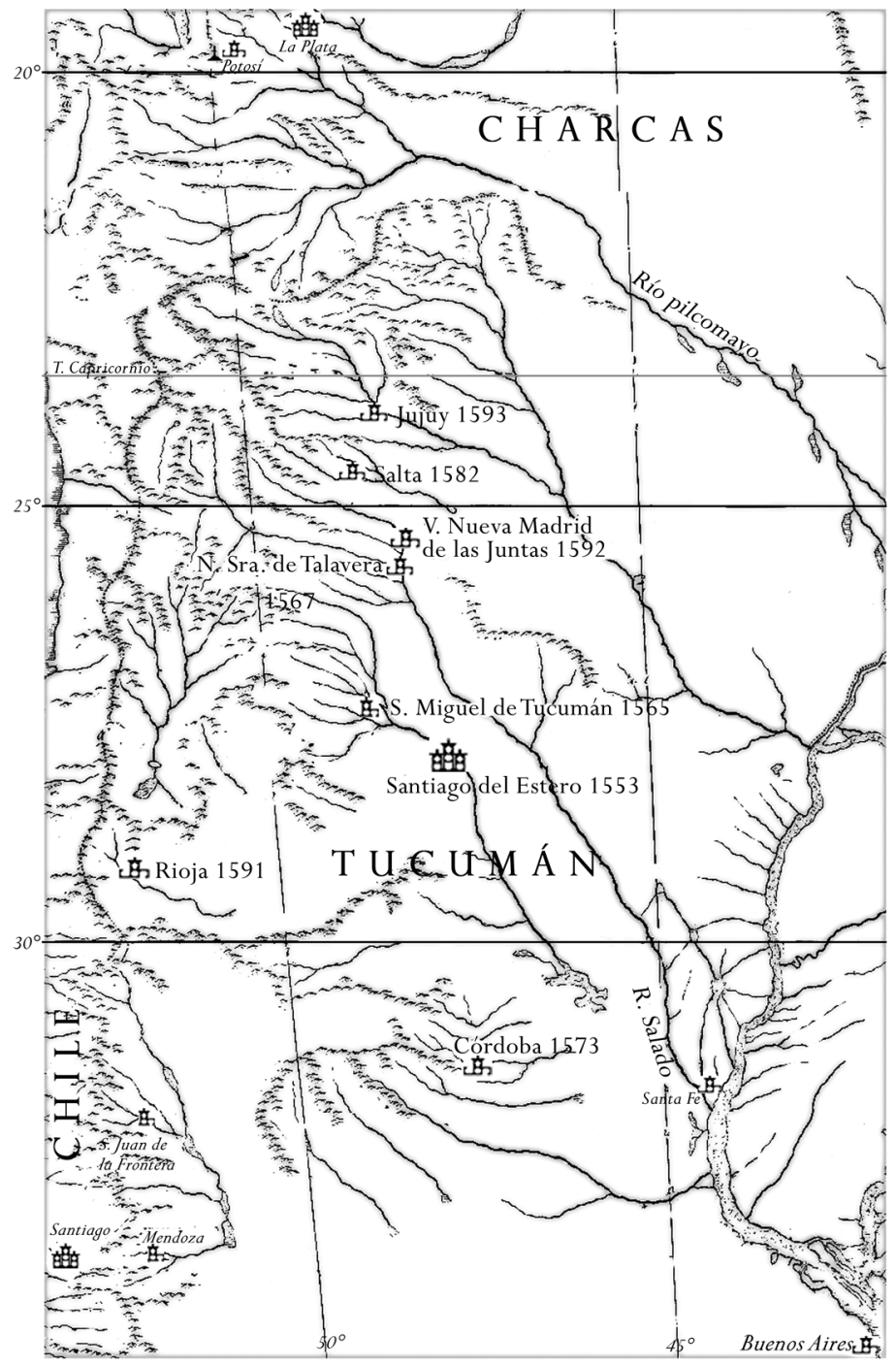

Fuente: reconstrucción a partir de Kitchin (1790, pp. 34-35).

\section{(ㄷ)(1) $\$$}


clérigos, y después que yo salí -anotó el obispo- el uno se fue huyendo de la furia del que gobierna al Paraguay, y el otro se murió; sólo quedan en la tierra hasta doce frailes de las órdenes mendicantes."

Dos años después, en 1586, el nuevo gobernador, Juan Ramírez de Velasco, elaboró una información con testigos para dar cuenta de la gran necesidad de clérigos en el territorio. ${ }^{10}$ Para entonces, había algunos recién ordenados; sin embargo, pocos eran quienes los conocían, pues sólo dos testigos pudieron dar cuenta de sus nombres. Se trataba de "el padre Pedroso, el padre Juanes, el padre Francisco de Mesa y el padre bachiller Francisco de Aguilar, el padre Barrasa, el padre Miguel G., e otros dos o tres, que no se acuerda como se llaman". ${ }^{11}$ Es decir, había ocho o nueve clérigos seculares en toda la gobernación.

El número de frailes no era más alentador. Los mercedarios, quienes habían sido los primeros en llegar al Tucumán, tenían casa poblada en las ciudades de Nuestra Señora de Talavera y Santiago del Estero, donde residía el comendador, quien vivía enfermo. En toda la gobernación eran cuatro o cinco, la mayoría recién llegados. Los franciscanos eran catorce o quince, entre sacerdotes y legos, y tenían casas en Santiago del Estero, San Miguel de Tucumán, Córdoba y Nuestra Señora de Talavera; en Salta la estaban construyendo. A ellos se sumaban dos jesuitas quienes habían llegado en 1586, Francisco de Angulo y Alonso Barzana, los cuales "a pocos días fundaron en ella casa de su Compañía del nombre de Jesús, y son letrados y el uno predicador, e predica también a los naturales en su lengua”. Al año siguiente, 1587, llegarían cuatro o cinco jesuitas más, procedentes del Brasil. En total, señaló el gobernador, había 36 sacerdotes en toda la provincia, ${ }^{12}$ contando al dominico, fray Francisco Vázquez.

Hasta el final del siglo la situación no mejoraría sustancialmente. En casi todas sus cartas, Juan Ramírez de Velasco solicitó se enviaran clérigos y frailes e igual lo haría Pedro Mercado. ${ }^{13}$ El primero escribió en 1596:

${ }^{10}$ Carta del gobernador Juan Ramírez de Velasco. 10 de diciembre de 1586. Charcas, 26, R. 5, N. 11. AGI, Sevilla (publicada por Levillier, 1920, vol. I, pp. 177-194).

${ }^{11}$ Información de oficio sobre el estado de la iglesia de Santiago. 11 de noviembre de 1586. Charcas, 26, R. 5, N. 10. Otra copia en Charcas 78, N. 43. AGI, Sevilla.

${ }_{12}$ Carta del gobernador informando de las cosas de la iglesia catedral. 10 de octubre de 1587 (citada en Levillier, 1920, vol. I, p. 227).

${ }^{13}$ Mercado fue nombrado gobernador en 26 de abril de 1593. Buenos Aires 5, L. 1, fs. 60v-62. AGI, Sevilla.

\section{(ㅇ)(1) $\$$}


Ya tengo escrito que hay diecisiete sacerdotes, cinco de la Compañía de Jesús, que estos donde quiera son de provecho por su ejemplar vida y costumbres. De la orden de Señor San Francisco hay tres, dos en esta ciudad y uno en Santa Fe, y de la de Nuestra Señora de la Merced, dos, el uno aquí y el otro en la ciudad de [¿Talavera?] y siete clérigos; conforme a esto verá vuestra majestad cual está todo este obispado y la necesidad que tiene de remedio. ${ }^{14}$

El escaso número de frailes y clérigos era aún más notable debido a la extraordinaria dimensión del territorio tucumano, así como a la dificultad de los caminos, su inseguridad, la abrupta geografía, lo belicoso de algunos grupos indígenas, las enormes distancias entre áreas pobladas y la falta de medios de transporte.

Si bien ese panorama hacía que fuera necesario un establecimiento para la formación de clérigos, quienes pudieran ocuparse de la administración de los sacramentos entre españoles y la evangelización de naturales, muy difícilmente podría haberse erigido un seminario tridentino. Este debía sostenerse de rentas eclesiásticas, pero no había de dónde cobrarlas, pues no había curatos ni doctrinas suficientes y tampoco prebendas catedralicias; de hecho ni siquiera estaba claro quiénes eran los beneficiados de catedral.

En los "Estatutos de erección" de la catedral elaborados por el obispo Victoria en 1578, el Cabildo catedralicio se instituyó con las 27 prebendas clásicas de todos los americanos. ${ }^{15}$ No obstante, según se estipuló, dicho número se iría ocupando conforme las rentas de la Iglesia fueran mayores y, mientras tanto, se prescindiría de arcediano, tesorero, cinco canonjías y tres medias raciones. Previsión que no fue suficiente.

En El primitivo obispado del Tucumán..., Julián Toscano (1907, vol. I, p. 53) anotó cómo dada la penuria de sacerdotes, algunas de las sillas canonicales fueron otorgadas, en un principio, a miembros del clero regular, conforme a un privilegio otorgado por la Santa Sede al obispo Albornoz. ${ }^{16}$ Yo no he podido encontrar datos para corroborar lo dicho, ${ }^{17}$ pero, sea como fuere, Sevilla.

${ }^{14}$ Carta del gobernador Juan Ramírez de Velasco, 1596. Charcas, 26, R. 5, N. 30. AGI,

${ }^{15}$ Los estatutos de erección en Muriel (1776, pp. 232-235).

${ }^{16}$ Eso había asegurado Córdoba y Salinas (1957, vol. I, p. 574), quien señaló se trataba de siete franciscanos.

${ }^{17}$ Fray Jerónimo de Albornoz, en efecto, pasó a Indias con un compañero y seis religiosos, pero eso fue en 1566 para atender en Nueva España a "la instrucción y conversión de los indios naturales". Cuando se embarcó como obispo para Tucumán en 1575, lo hizo sólo en

\section{(ㅇ)(1) $\$$}


es claro que el nombramiento de prebendados fue uno de los principales problemas de la catedral de Santiago del Estero durante el siglo XVI.

El mismo año de su nombramiento como obispo, fray Francisco de Victoria solicitó se le concediera la facultad de nombrar cuatro beneficiados catedralicios, en tanto el rey les proveía, pues, como antes de él no había llegado prelado alguno, no se habían elegido dignidades ni canonjías. ${ }^{18}$ Gracias a esa autorización, el obispo nombró deán y chantre mientras estaba en la ciudad de Lima; luego, en la Villa de Potosí, designó arcediano y volvió a hacer el nombramiento de chantre, pues, al parecer, el primer designado renunció sin llegar a Santiago del Estero. ${ }^{19}$ De hecho, de los primeros capitulares así nombrados, el único con una presencia relativamente constante fue el deán Francisco de Salcedo. ${ }^{20}$

En 1584 el obispo escribió diciendo cómo en su catedral sólo estaba el deán, único que podía sustentarse con los 700 pesos corrientes de la cuarta capitular. ${ }^{21}$ Luego, a mediados de 1587 , quizá porque las rentas habían aumentado, el obispo volvió a hacer uso de su facultad para proveer de ministros a su Iglesia, y así el Cabildo quedó conformado por cuatro dignidades y un canónigo. ${ }^{22}$ A pesar de los nuevos nombramientos, ese año nadie se encontraba en catedral. El maestrescuela esperaba en Buenos Aires la llegada del tesorero, y otro prebendado se había ido con el obispo a Brasil, mientras que los restantes habían sido privados de sus oficios por el dominico fray Francisco Vázquez, quien ejercía el cargo de administrador de la catedral por orden del prelado. ${ }^{23}$

compañía de Diego López y Alonso de Salamanca, clérigo presbítero. Véase Contratación, 5221, N. 3, R. 2 e Indiferente, 2087, N. 87. AGI, Sevilla.

${ }^{18}$ Licencia al obispo de Tucumán para nombrar beneficiados. 28 de diciembre de 1578. Buenos Aires, 5, L. 1, fs. 27v-28. AGI, Sevilla. La medida estaba prevista en la ordenanza del patronato de 1574 .

${ }^{19}$ Se trataba del deán Francisco de Salcedo, el chantre Sanabria, el arcediano Fernando Rojas y el nuevo chantre, Diego Pedrero. Informaciones de oficio y parte de Pedro Farfán. Charcas 82, N.12.f. 19. AGI, Sevilla.

${ }^{20}$ Carta del obispo Victoria al rey. 8 de diciembre de 1582. Charcas, 137. AGI, Sevilla.

${ }^{21}$ Carta del obispo Victoria al rey. 6 de abril de 1584 (citada en Pastells, 1912, vol. I, p. 25). En la mayoría de las catedrales la cuarta capitular correspondía a $25 \%$ de los diezmos.

${ }^{22}$ Estos eran el deán Francisco de Salcedo, Gerónimo Pedroso, como nuevo chantre, el maestrescuela Fernando de Aguilar, el tesorero, llamado también Francisco de Salcedo y el canónigo Juan de Quiroz. El deán fue nombrado en Lima en 1582 y, su sobrino Francisco recibió la canónica institución como tesorero en Santiago del Estero el 7 de agosto de 1587. Charcas, 82, N. 12. AGI, Sevilla.

${ }^{23}$ Carta del gobernador informando de las cosas de la iglesia catedral. 10 de octubre de 1587 (citada en Levillier, 1920, vol. I, p. 227).

\section{()(1) $\$$}


En los años siguientes las ausencias continuarían, pues los capitulares debieron invertir mucho tiempo en la audiencia de Charcas, para poder conservar sus prebendas. Y es que, debido a un pleito promovido por el deán, aquella audiencia declaró que el obispo Victoria no tenía facultad para nombrar dignidades catedralicias, sino simplemente cuatro clérigos. ${ }^{24}$ El conflicto así desencadenado continuaría hasta los primeros años del siglo XVII, debido, sobre todo, a la falta de comunicación con Madrid, pues ni en el Consejo de Indias ni en la audiencia de Charcas estaba claro quiénes detentaban las prebendas ${ }^{25}$ Por tanto, no podría haberse tomado una parte de sus rentas para crear un colegio tridentino.

Además, a raíz de esos conflictos, desde 1590, cuando Victoria dejó el obispado, y hasta 1595, no hubo en el Tucumán quien pudiera ejercer jurisdicción eclesiástica, pues ninguno de los prebendados tenía presentación real. ${ }^{26}$ Así, cuando el nuevo obispo, fray Francisco de Trejo y Sanabria (15951614), requirió a los capitulares lo recibieran en el gobierno, el arcediano señaló cómo, según el patronato, sin presentación no podían los prebendados tener jurisdicción, y no teniéndola mal la podrían compartir o ceder.

A esa diócesis inmensa y poco comunicada, sin clérigos, con un cabildo ausente y falto de jurisdicción, se sumaron, para incrementar su inestabilidad, los conflictos políticos de su polémico primer obispo, quien fue acusado por particulares, así como por gobernadores y cabildos de ciudades, debido a sus constantes ausencias y porque su vida no era "de prelado, sino de mercader". ${ }^{27}$

Del proceder de Francisco de Victoria se quejaría también el arzobispo Toribio Mogrovejo, pues durante las reuniones del tercer concilio limeño, Victoria estuvo entre aquellos que cuestionaron la jurisdicción del arzobispo y obligaron a la suspensión de la asamblea. ${ }^{28}$ Debido a los enfrentamientos

${ }^{24}$ Informaciones de oficio y parte de Pedro Farfán. Charcas, 82, N. 12. f. 19. AGI, Sevilla.

${ }^{25}$ Muestra de ello es cómo el rey otorgó el deanato a Salcedo desde 1585 y, no obstante, la audiencia y el obispo lo destituyeron tres años después, por lo que se le volvió a expedir el nombramiento en 1592. En el caso contrario se encontró Pedro Farfán, quien ocupaba el arcedianato por nombramiento de Victoria desde 1589, pero como no se sabía de ello en la Corte, el rey presentó en la misma prebenda a Miguel de Milla en 1599, quien sólo pudo tomar posesión de su prebenda hasta 1603. Prorroga a Francisco de Salcedo. 13 de mayo de 1592. Buenos Aires, 5, L. 1, fs. 38v-39; Registro eclesiástico general. Indiferente, 2859, L. 3. AGI, Sevilla.

${ }^{26}$ Informaciones de oficio y parte de Pedro Farfán. Charcas, 82, N. 12. f. 19. AGI, Sevilla.

${ }^{27}$ Carta de Juan Ramírez de Velasco, junio 29 de 1587 (citada en Levillier, 1920, vol. I, p. 214).

${ }^{28}$ Según Mogrovejo, fue Victoria quien secuestró las actas del concilio y provocó su paro temporal. Cartas de Toribio Alfonso Mogrovejo. 27 de abril de 1584. Patronato, 248, R. 10. AGI, Sevilla.

\section{()(1) $\$$}


allí suscitados, cuando en 1584 Victoria solicitó por primera vez que se le admitiera la renuncia de su sede, el arzobispo limeño recomendó se le aceptara, por lo cual esta se empezó a tramitar en Roma en 1587 y dos años después, el obispo dejó su sede. ${ }^{29}$

En marcado contraste con las quejas elaboradas por sus contemporáneos, el jesuita Pedro Lozano hizo una apología de la vida de Victoria. Y es que, como es sabido, a las negociaciones de ese obispo se ha atribuido la introducción de los jesuitas al Tucumán (Astrain, 1913, vol. IV, pp. 605-608).

Así, en su Historia de la Compañía de Jesús, Lozano (1754, vol. 1, p. 33) pintó a un joven inquieto en búsqueda de fortuna que, luego de una revelación divina, cambió su conducta y adoptó el hábito de la orden de predicadores. Ya como obispo -señaló el cronista jesuita-, Victoria se dedicó con todo empeño a extirpar los abusos que halló en su diócesis, la visitó toda sin ostentación, socorrió a los pobres, desagravió a los miserables indios y no desistió hasta proveerla de ministros aptos para predicar el evangelio y "para esto, principalmente, se valió de nuestra mínima Compañía".

A continuación, Lozano (1754) trató de explicar y justificar el proceder del obispo durante las reuniones del tercer concilio limeño, con la intención de dejar "vindicado el honor y buen nombre de prelado tan insigne". Precisamente, en el marco de ese intento de reivindicación, Lozano (1754) atribuyó al obispo Victoria el establecimiento, en 1587, del primer seminario conciliar en Santiago del Estero. Señala el cronista que luego de la llegada de los jesuitas, el obispo había procurado se abrieran escuelas para la enseñanza pública, y puso "igual empeño en la erección del seminario, donde se criasen ministros hábiles para el servicio de la santa Iglesia, según prescribe el santo Concilio de Trento" (p. 38).

Al respecto, y siguiendo al cronista jesuita, Luis Roberto Altamira (1943) señaló que aquel fue un establecimiento modesto y efímero, creado en un periodo difícil para la Iglesia del Tucumán, el cual debió apagarse entre los pleitos de Victoria con los gobernadores Hernando de Lerma y Juan Ramírez Velasco "entre las persecuciones de clérigos y religiosos, que huían rumbo a las fronteras; $y$ entre los bandos, los chismes, las simulaciones, los sacrilegios y las groserías de los segundones sin escrúpulos" (p. 15).

${ }^{29}$ Consulta del consejo sobre la dimisión del obispo de Tucumán. 8 de mayo de 1587; Real cédula al conde de Olivares, embajador en Roma. 16 de julio de 1587. Charcas, 1, N. 37. AGI, Sevilla.

\section{(이요 $\$$}


Sin embargo, más allá de lo asegurado por Lozano, no existen indicios documentales de ese primer establecimiento $y$, de hecho, ni siquiera puede suponerse su existencia. Según prescribió Trento, el gobierno de los colegios debía estar a cargo del obispo y vinculado al Cabildo, pero una característica de la Iglesia del Tucumán en esos primeros años fue la inestabilidad del Cabildo y del gobierno episcopal de su primer prelado. Además, los seminarios debían financiarse con las rentas eclesiásticas de cada obispado, pero en Santiago no había de dónde cobrarlas, dado lo precario de las rentas capitulares, la falta de curas párrocos o doctrineros y la pobreza de los existentes.

Así, lo único que se puede asegurar es que la fundación del seminario, creado años después por Trejo y Sanabria, estuvo determinada en buena medida por las necesidades de esa diócesis en construcción, inmensa y sin clérigos, dejada por el obispo Victoria.

\section{LA RENOVACIÓN DE LA IGLESIA DIOCESANA}

El año de 1595, cuando tomó posesión de su sede fray Hernando Trejo y Sanabria, anunció el inicio de una nueva época para la Iglesia del Tucumán. Pocos años después el obispado se dotaría de normas propias gracias a la celebración de tres sínodos provinciales $(1597,1606,1607)$, los prebendados recibirían nombramientos y se constituirían como un verdadero Cabildo, los diezmos aumentarían, se darían las bases para la organización del régimen parroquial y, por tanto, finalmente, se podría crear un seminario conciliar, aunque no en Nueva Madrid de las Juntas.

A partir de 1603, gracias a las negociaciones realizadas en la Corte por los miembros del Cabildo, este llegó a tener cinco prebendados, todos con presentación real. ${ }^{30}$ Salvo el tesorero Salcedo, quien ascendió a una canonjía en Charcas, el resto de los capitulares murió en la catedral, como lo haría también la inmensa mayoría de quienes ingresaron al Cabildo en los años posteriores. ${ }^{31}$ A esa regularización de la vida capitular sin duda contribuyó el

30 Se trató de las dignidades de deán, arcediano, chantre, maestrescuela y tesorero, que en ese año ocupaban Tomé Salinas, Miguel de Milla, Pedro Farfán, Francisco de Aguilar, y Francisco de Salcedo, respectivamente.

${ }^{31}$ Por lo menos hasta 1658, cuando Pedro de Rojas ascendió a una canonjía en Cartagena. Los nombramientos en, Registro eclesiástico general. Indiferente, 2859, L. 3; y Registro eclesiástico del Perú. Indiferente, 2860, L. 4 y L. 5. AGI, Sevilla.

\section{(ㅇ)(1) (}


alza en los diezmos del obispado, pues, precisamente, hubo un crecimiento a partir del periodo 1595-1596 (véase gráfica 1).

Silvia Palomeque (2005, pp. 45-75) ha señalado diversos factores que pudieron haber contribuido a ese incremento del diezmo. Por lo que a nosotros interesa, es claro cómo esa mejoría económica contribuyó a la estabilidad del Cabildo y de la misma catedral, pues del diezmo dependían no sólo las prebendas sino el funcionamiento del culto divino. En ese sentido, en septiembre de 1596 el Cabildo destinó 250 pesos para aderezar el órgano $y,{ }^{32}$ al año siguiente, se adoptaron medidas para regularizar el servicio del culto, al nombrar al canónigo Pedro Guerrero y al padre Antonio Saa para acudir al coro y al altar "como si fueran capitulares". ${ }^{3}$

Más importante aún fueron las determinaciones tomadas en 1601 respecto de la administración del diezmo, pues entonces se dieron plenos poderes a uno de los prebendados, para arrendarlo y cobrarlo y, además, se nombró mayordomo. ${ }^{34}$ Oficio indispensable para la eficiente administración del diezmo en toda catedral, y del cual había carecido hasta entonces la Iglesia de Santiago.

Ahora bien, la normalización de la vida capitular se favoreció también gracias a la labor legislativa del obispo Trejo y Sanabria. En particular, debido al segundo sínodo, convocado en 1606, pues en la mayoría de sus normas se atendió a las tareas del Cabildo, su asistencia al coro, los oficios divinos y fiestas, el hábito que debían portar, el recle y la periodicidad de las reuniones capitulares. ${ }^{35}$

Con todo, si bien las actividades de la catedral y del Cabildo tendieron a regularizarse, la falta de clérigos siguió siendo un problema constante. Como vimos, hasta finales del siglo xvi los gobernadores repitieron una y otra vez la necesidad de contar con más ministros para la prédica y la conversión de los indios. Lo más importante, decía Pedro Mercado en 1596, sería se autorizaran más miembros de la Compañía de Jesús, porque "hacen esto con tan particular afecto, que parece que los señala y extrema nuestro Señor entre

32 Acta capitular. 11 de septiembre de 1596 (citada en Palomeque, Castro, Tell, Crouzeilles y Tedesco, 2005).

${ }_{33}$ Acta capitular. 9 de noviembre de 1597 (citada en Palomeque et al., 2005).

${ }^{34}$ Sobre el administrador del diezmo en Acta capitular, 17 de agosto de 1601. El nombramiento de mayordomo en Acta capitular, 19 de agosto de 1601 (citadas en Palomeque et al., 2005).

${ }^{35}$ Las actas del sínodo citadas en Levillier (1926, vol. I, p. 47).

\section{()(1) $\$$}




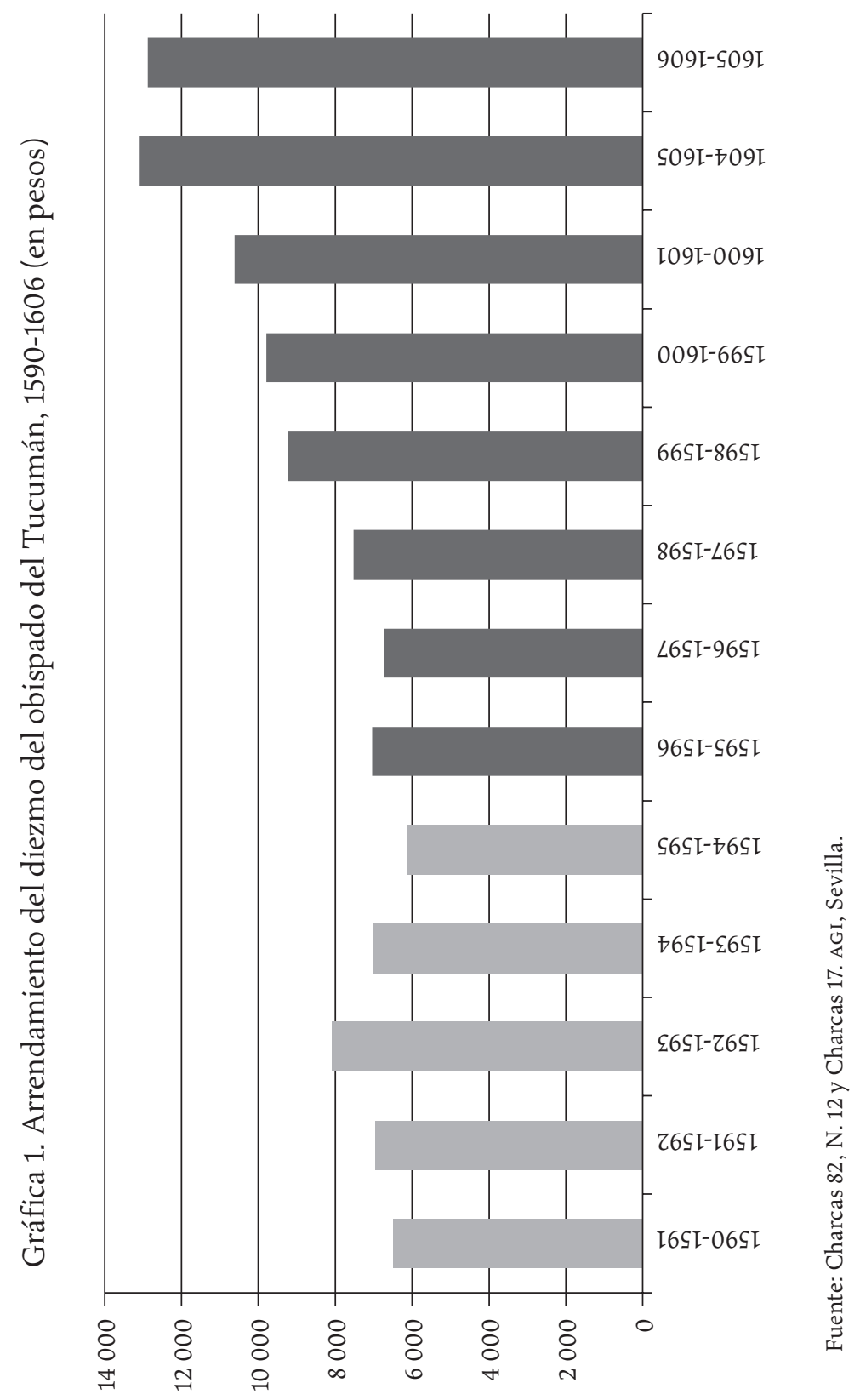

\section{(ㅇ)(1) $(3$}


los demás religiosos, porque no tratan de interés humano, sino sólo del bien de estas almas". ${ }^{36}$

$\mathrm{Al}$ año siguiente, según se informó en el Consejo de Indias, se había mandado proveer de lo necesario a Felipe Clavel para ir con 20 jesuitas hacia Chile, Santa Cruz de la Sierra y Tucumán. Además, se ordenó al virrey del Perú informarse sobre la falta de doctrina, y dar cumplimiento a una cédula de 1593, donde se le había ordenado juntar a los provinciales de las órdenes para que estos enviaran frailes al Tucumán, aunque los conventos de Perú quedaran con muy pocos. ${ }^{37}$ Sin embargo, la orden no se cumplió.

A partir de los años setenta del siglo xvi, la política real para las Indias tuvo entre sus objetivos fortalecer a la Iglesia secular y disminuir el poder e influencia que habían adquirido las órdenes mendicantes..$^{38}$ En ese sentido, explicó el virrey Francisco de Toledo, con la creación de seminarios y universidades se podría favorecer "lo eclesiástico de San Pedro, que está flaco, e ir rebajando la insolencia de los frailes" ${ }^{39}$ Pero, hasta haber "clérigos de la cosecha", era necesario sobrellevar a las órdenes religiosas, "tirándolas de la rienda para que vayan siendo de ayuda, y no más, metiéndose a los ordinarios en la posesión de la jurisdicción". ${ }^{40}$

Todo indica que esa misma política siguió teniendo vigencia en el Tucumán, por lo menos hasta principios del siglo XVII, pues las casas mendicantes de la gobernación no volvieron a recibir más miembros. De hecho, la iglesia y casa franciscana de la ciudad de Jujuy quedó despoblada para $1610 .{ }^{41}$

El sínodo de Trejo y Sanabria, reunido en septiembre de 1597, también da muestra de la falta de apoyo a las órdenes mendicantes, pues originalmente se declaró que uno de los puntos principales a tratar sería la distribución de las doctrinas, por la falta de sacerdotes y frailes. ${ }^{42}$ Sin embargo, al final, ninguna de las normas se refirió a esa distribución, pues la intención fue facilitar y fomentar la ocupación de parroquias por clérigos seculares.

${ }^{36}$ Carta de Pedro Mercado. 20 de julio de 1596 (citado en Levillier, 1920, vol. I, p. 325).

${ }_{37}$ Carta de Pedro Mercado. 20 de julio de 1596 (citado en Levillier, 1920, vol. I, p. 325).

${ }_{38}$ Me refiero a los acuerdos tomados en la Junta Magna de 1568. Sus documentos en el libro Apuntamientos de materias de Indias hechos desde el año de 1568 hasta el de 1637. Legajo 41. Archivo General del Ministerio de Justicia (en adelante AGMJ), Madrid. Véase Pérez (2010a).

${ }^{39}$ Carta del virrey Toledo. 30 de noviembre de 1573 (citada en Levillier, 1924, vol. v, p. 229).

${ }^{40}$ Carta del virrey Toledo. 20 de marzo de 1573 (citada en Levillier, 1924, vol. v, pp. 7-26).

${ }^{41}$ Carta del obispo del Tucumán en respuesta a varias reales cédulas. 4 de noviembre de 1610 (citada en Levillier, 1926, vol. I, pp. 90-94).

${ }^{42}$ Las actas del sínodo citadas en Levillier (1926, vol. I, p. 10).

\section{(ㅇ)(1) $\$$}


Con ese mismo interés, el sínodo celebrado en 1606 incluyó diversas normas para dotar con mayores recursos a los curatos. Por ejemplo, en el capítulo 12 se dio a las Iglesias de La Rioja, Salta, Nueva Madrid de las Juntas y Jujuy, la mitad del diezmo escusado de esas ciudades; el capítulo 19 mandó hacer aranceles para la paga de los derechos de jueces eclesiásticos y ministros curas, sacristanes y visitadores, y en el capítulo 20 se ordenó el reparto de las ofrendas de días festivos y ordinarios entre los curas y los capitulares (Levillier, 1926, vol. I, p. 47). Es más, en la práctica, en ciudades como La Rioja, el diezmo colectado se otorgó enteramente al cura párroco durante algún tiempo. ${ }^{43}$

Pero, por más que las parroquias se hicieran atractivas gracias a una mejor dotación, no se solucionaban los problemas. La diócesis era enorme y los clérigos seculares recién llegados siempre aspiraban a regresar a sus tierras y promoverse en ellas. De hecho, cuando en 1597 se ofreció al padre Juan Gutiérrez acudir al coro y al servicio del altar en catedral, respondió: "por cuatrocientos cincuenta pesos que le ofrecen, no está por servir a la dicha iglesia ni el canto, porque está contra su voluntad en esta ciudad". ${ }^{4}$

Así, resultaba una mejor opción formar a los clérigos en la misma diócesis, pues allí tenían familiares para auxiliarles. Además, con ello se contribuiría al asentamiento de las ciudades, pues los jóvenes no tendrían que desplazarse a La Plata o Lima en búsqueda de estudios.

Precisamente, para dar estudios a los jóvenes, el sínodo de 1597 ordenó se fundara el seminario conciliar "donde puedan ser criados los mancebos en ciencia de virtud y letras, y para que los que aspiran a la dignidad sacerdotal, comiencen temprano a ser cultivados en el temor santo de dios y en los estudios en que se han de emplear". ${ }^{45}$

De acuerdo con el sínodo, el seminario se erigiría en la villa de Nueva Madrid de las Juntas, pues se trataba de un lugar céntrico "y porque tiene buena comunidad para el sustento y quietud que se requiere para estudiantes" ${ }^{46}$ Para el sostenimiento de la institución se ordenó cobrar, a partir de ese

${ }^{43}$ Existe registro de que así se hizo en el periodo 1595-1596 y, posiblemente, siguió la donación hasta 1598. Valor de los diezmos desde el año de 1581 hasta el de 1601. 25 de febrero 1601. Charcas 82, N. 12. AGI, Sevilla.

${ }^{44}$ También el canónigo Pedro Guerrero anunció en 1598 que dejaría la tierra. Actas capitulares de 9 de noviembre de 1597 y 25 de agosto de 1598 (citado en Palomeque et al., 2005).

${ }^{45}$ Constituciones y declaraciones aprobadas en el primer sínodo que hizo celebrar el obispo del Tucumán, 1597. Parte $3^{a}$, Constitución 15 (citado en Levillier, 1926, vol. I, p. 37).

${ }^{46}$ Constituciones y declaraciones aprobadas en el primer sínodo que hizo celebrar el obispo del Tucumán, 1597. Parte 3a , Constitución 15 (citado en Levillier, 1926, vol. I, p. 37).

\section{()(1) $(3$}


año, 3\% de las rentas eclesiásticas y se acordó pedir al rey sus dos novenos del diezmo, parte de las penas de cámara y condenaciones pecuniarias. Además, se solicitaría a los padres de los estudiantes dar a estos lo necesario para sustentarse, en tanto había más abundancia de frutos y rentas.

Ahora bien, cabe preguntarse por qué se pensó en Nueva Madrid de las Juntas para establecer el seminario, cuando Santiago del Estero era la sede episcopal y tenía una población importante.

En el censo elaborado en 1608 se registraron en Santiago 40 jóvenes menores de catorce años. Número de estudiantes potenciales que, es de suponer, se fue incrementando, sobre todo porque nueve de los varones censados sólo tenían dos hijos menores de nueve años y, es de creer, aumentarían su prole. Además, según el censo, había también 35 hombres solteros, susceptibles de tener hijos en un futuro. ${ }^{47}$

No poseo el censo de Nueva Madrid de las Juntas, pero muy probablemente registró pocos vecinos, pues se trataba de una villa nueva, fundada en 1592; es decir, a apenas cinco años de haberse ordenado la creación del seminario, por lo cual, quizá, se esperaba que con este se pudiera arraigar mayor población.

Con independencia del número de habitantes, la villa de las Juntas destacó a finales del siglo xvi por la rapidez en el crecimiento de sus diezmos. Como vimos, el diezmo del obispado presentó una tendencia al alza, acentuada a partir de 1595-1596. Fenómeno debido a un incremento importante en lo recaudado en las ciudades de Córdova, San Miguel de Tucumán y Nueva Madrid de la Juntas, en el periodo 1598-1599.

Como se puede apreciar en el cuadro 1, la ciudad de Santiago del Estero aportaba la mayor parte del diezmo, 26.75\% del colectado entre 1591 y 1601. Sin embargo, se trató de la única ciudad donde no hubo un crecimiento, antes bien registró una tendencia a la baja. ${ }^{48}$ En efecto, de 1592 a 1597 el diezmo de Santiago disminuyó en $74 \%$, y a partir de entonces no volvió a recuperar los 2175 pesos que, en promedio, había alcanzado en años anteriores. ${ }^{49}$

${ }^{47}$ Los datos sobre la población se han estimado a partir del padrón publicado por Doucet (1998, pp. 497-542).

${ }_{48}$ Arrendamientos de los diezmos de este obispado de Tucumán. 22 de febrero de 1601. Charcas, 82, N. 12. AGI, Sevilla.

${ }^{49}$ En el documento se anota que los diezmos del periodo 1593-1594 fueron cobrados por oficiales reales, debido a la sede vacante, lo cual muy posiblemente trataba de explicar que esa disminución no era debida a una mala administración del Cabildo, sino a las decisiones tomadas por los oficiales.

\section{(이요 $\$$}




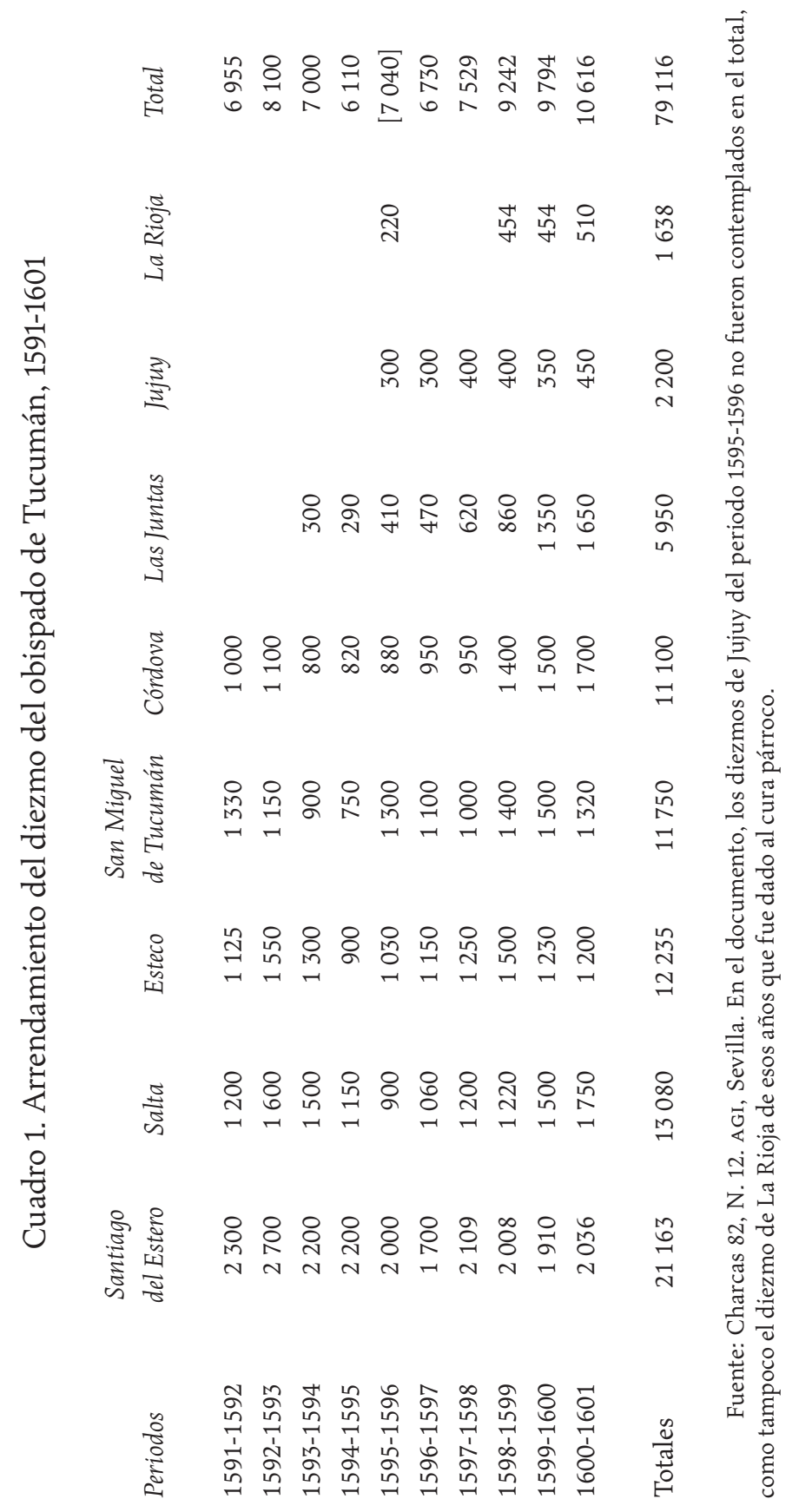

\section{(이)(1)}


Por el contrario, Nueva Madrid de las Juntas destacó por su aumento a partir de 1593, cuando su administración se separó de la de Esteco. En este caso, los diezmos inician en el periodo 1593-1594 con 300 pesos, llegan a los 620 en el periodo $1597-1598$ y, finalmente, alcanzan los 1650 pesos en $1600-$ 1601. Su crecimiento es, pues, notable (véanse gráficas 2 y 3 ).

Así, la elección de la villa de Las Juntas para establecer el seminario parece clara, pues además de su centralidad -como decía el obispo Trejo-, era una ciudad muy promisoria, o al menos parecía serlo hasta $1601 .^{50}$

Con todo, no podemos saber si lo dispuesto en el sínodo se cumplió cabalmente. Si bien lo dan por hecho la mayoría de los autores, ${ }^{51}$ yo no he podido encontrar rastro documental de un seminario en aquella villa, y no puede suponerse que así fue sólo porque el sínodo lo ordenó. Sólo existen claras referencias, en relación a que el seminario empezó a funcionar en Santiago del Estero antes de 1606.

En 1601 Trejo y Sanabria escribió al rey diciendo cómo debido a la pobreza de la Iglesia no era posible tener un colegio seminario donde se pudieran instruir aquellos que debían acudir al ornato y culto divino, lo cual era "una de las cosas más convenientes a la autoridad de una catedral" ${ }^{52}$ Luego, en respuesta a una consulta del rey, el gobernador Alonso de Rivera escribió señalando que, según había visto desde su llegada en 1606, no había colegio seminario en la ciudad, ni colegiales, sino sólo un aposento cerca de las casas episcopales, donde un seglar nombrado por el prelado enseñaba gramática a diez o doce estudiantes. A este, según dijo, se le pagaban alrededor de 650 pesos corrientes, de a ocho reales, tomados de toda la masa de los diezmos y la renta de las capellanías, doctrinas y beneficios eclesiásticos del obispado. ${ }^{53}$

Por su parte, el tesorero de la catedral también informó que no había seminario, tal y como lo habían dicho el gobernador y el prelado, ${ }^{54}$ y respaldando sus peticiones habló del provecho que se seguiría a los hijos y nietos de conquistadores y pobladores así como a los indios. Además, sugirió encargar el establecimiento a la Compañía de Jesús, pues lo tendría con puntualidad, cuidado, policía y cristiandad y, sobre todo, con menor costo. Bastaría con

50 Sobre las fluctuaciones del diezmo, véanse las consideraciones de Palomeque (2005).

${ }^{51}$ Según Altamira (1943, pp. 23-24), allí debió estar el colegio de 1596-1597 hasta principios del siglo.

${ }_{52}$ Carta del gobernador Alonso de Rivera, 1607 (citada en Levillier, 1926, vol. I, p. 5).

${ }^{53}$ Cartas y expedientes de gobernadores. Charcas, 26. AGI, Sevilla; Altamira (1943, apéndice 1).

${ }^{54}$ Informe del tesorero. Charcas, 17. AGI, Sevilla; Altamira (1943, apéndice 2).

\section{(이)(1)}


Gráfica 2. Arrendamiento del diezmo de Santiago del Estero, 1592-1601 (en pesos)

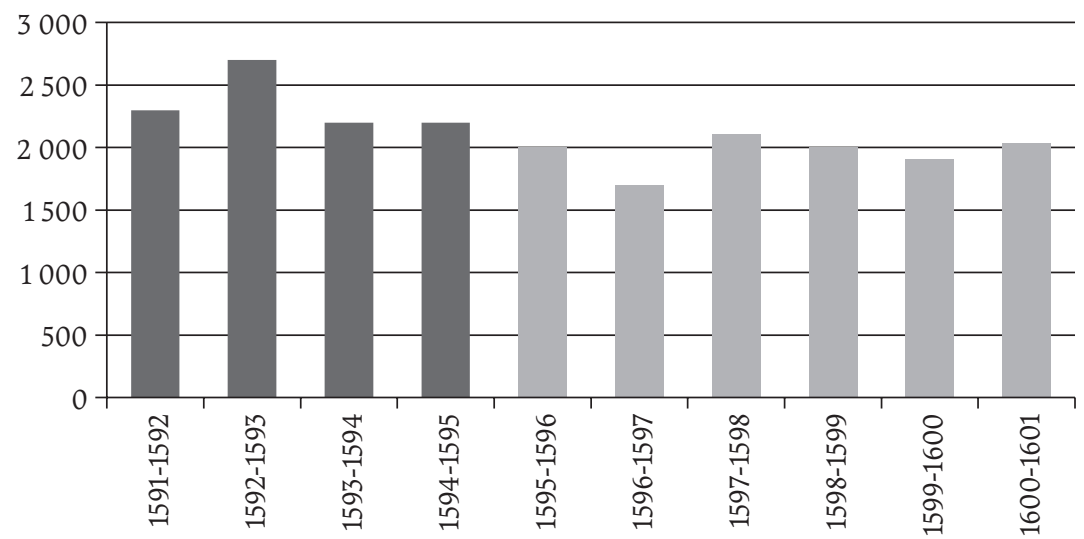

Fuente: Charcas 82 , N. 12. AGI, Sevilla.

Gráfica 3. Arrendamiento del diezmo de Nueva Madrid de las Juntas, 1591-1601 (en pesos)

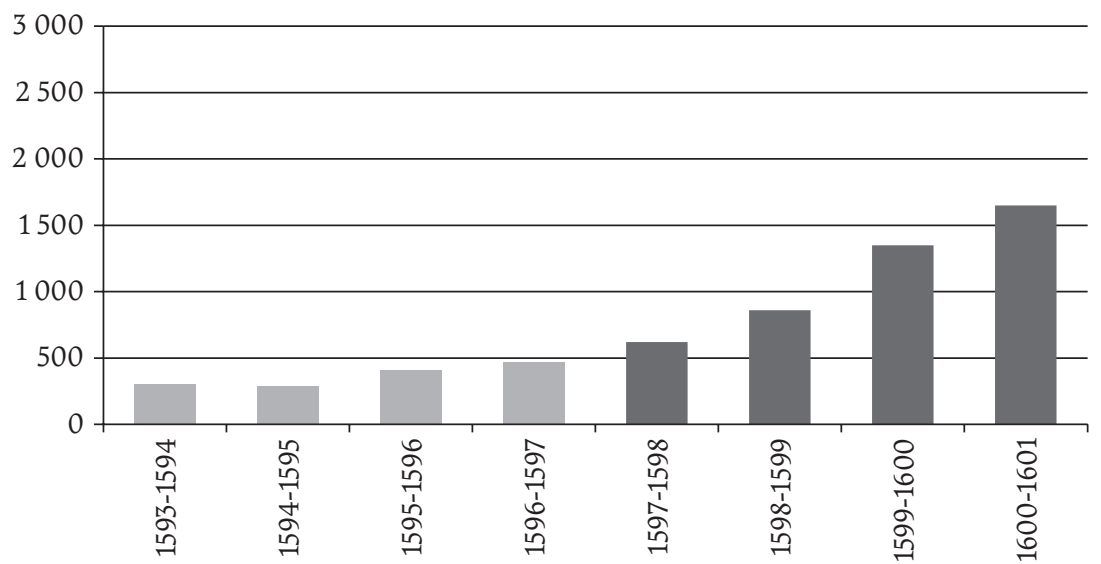

Fuente: Charcas 82 , N. 12. AGI, Sevilla.

\section{(ㅇ)(1) 8}


dar a los jesuitas los 650 pesos, y completarles hasta 2000 , con pensiones impuestas en nuevas encomiendas y la renta de los dos novenos del diezmo, correspondientes al rey.

Finalmente, en abril de 1607 se encargó al chantre Pedro Farfán -quien iría como procurador de la catedral a la península-, significar al rey la pobreza de la Iglesia y cómo esta no tenía ninguna renta para, entre otras cosas, "establecer ni fundar el colegio seminario", donde los hijos de la tierra pudieran aprender "letra, ciencia y virtudes". ${ }^{55}$

A pesar de lo dicho por todos, el 30 de julio de 1606 Trejo y Sanabria y el Cabildo habían formalizado el nombramiento del catedrático del seminario. En el acta capitular de ese día se asentó: "se admitió por preceptor en el seminario, que está de presente en esta ciudad, al licenciado Juan de Ocampo Jaramillo, que de presente lee en el dicho seminario". ${ }^{56}$

Así, el objetivo de aquellas misivas no era crear el seminario, sino establecerlo jurídicamente, pues, según lo dicho por todos, este existía antes de 1606 en un local contiguo a la casa episcopal. No se trataba de un colegio-residencia con cátedras y colegiales, sino tan sólo de una lectura de gramática latina, dictada por Ocampo Jaramillo, quien, nombrado por el obispo, recibía 650 pesos corrientes, de a ocho reales, procedentes de rentas eclesiásticas, lo que formalmente era un seminario tridentino.

Muchos seminarios llegaron a ser residencias de estudiantes, donde jóvenes aspirantes al sacerdocio vivían en comunidad y tomaban lecciones, guiados por un rector, como sucedió en Lima, Santa Fe de Bogotá, La Plata y Guatemala, pero en el siglo XVI no todos iniciaron así. El seminario de Quito, creado por fray Pedro de la Peña en 1569, fue similar al de Santiago del Estero, pues era una cátedra de latinidad leída en la parroquia de Santa Bárbara, la cual se pagaba de la cuarta episcopal y capitular, las doctrinas y curatos del obispado. También en Chile era igual, pues hasta antes de 1607 un clérigo leía gramática pagado de un fondo compuesto por 3\% de las rentas eclesiásticas del obispado de Santiago y lo mismo sucedía en La Imperial hasta antes de 1599, cuando se despobló la ciudad debido a la guerra (Pérez, 2010b, vol. II, pp. 219-242; 2012, vol. 1, pp. 177-196).

55 Acta capitular. 4 de abril de 1607 (citada en Palomeque et al., 2005).

${ }^{56}$ En 1608 se daría el mismo cargo a Juan de Alvarado. Actas capitulares de 30 junio de 1606 y 1 de julio de 1608 (citada en Palomeque et al., 2005).

\section{(ㅇ)(1) $\$$}


Así, aquellas misivas donde se negaban la existencia del seminario en realidad tenían por objetivo incrementar las rentas del establecimiento, ${ }^{57} \mathrm{y}$ formalizar jurídicamente su fundación, para así poder darlo a la Compañía de Jesús. Ello porque, como hemos visto, desde tiempos de Victoria, prelados y gobernadores suplicaron de manera reiterada se mandaran jesuitas, pues predicaban "a los naturales en su lengua e son de buena doctrina"; porque donde quiera eran de provecho, "por su ejemplar vida y costumbres"; porque "los señala y extrema nuestro Señor entre los demás religiosos" y por su "puntualidad, cuidado, policía y cristiandad" ${ }^{58}$ A lo anterior se sumaría la creencia, por parte del obispo Trejo, de que los jesuitas pretendían abandonar definitivamente el Tucumán.

Y cuando doné las haciendas de Yatasta [...] fue por haber entendido que los padres de la Compañía salían de esta gobernación, lo cual se tuvo por cierto, y con ellos que se frustraban mis buenos intentos [...] para los cuales verdaderamente yo fui haciendo las dichas fincas [...], y no la diera a mis sobrinos ni a ningún pariente, si entendiera que los dichos padres de la Compañía habían de permanecer en este obispado y gobernación. ${ }^{59}$

Ese interés manifiesto por la Compañía de Jesús hizo que el seminario se fundara formalmente y, a la vez, que se apartara del modelo tridentino, para pasar a convertirse en cuatro becas, cuyos titulares residirían y tomarían clases con los jesuitas.

\section{CUATRO BECAS PARA SEMINARISTAS DENTRO DE UN COLEGIO JESUITA}

El seminario del Tucumán tendría cambios importantes luego de su fundación formal, los cuales harían de él una institución distinta a la dispuesta por

${ }^{57}$ Quizá con la ambición de hacerlo semejante al colegio de La Plata, pues, para 1605 este tenía casa propia donde se alojaba un rector y 16 colegiales, quienes estudiaban gramática y servían a la catedral (Barnadas, 1995, p. 70).

${ }^{58}$ Cartas del gobernador Juan Ramírez de Velasco. 10 de octubre de 1587 y 1 de enero de 1597; Carta de Pedro Mercado. 20 de julio de 1596. Charcas, 26, R. 5, N. 30. AGI, Sevilla; Levillier (1920, vol. I, pp. 227 y 325).

59 Testamento de fray Fernando de Trejo y Sanabria, punto 2. Buenos Aires, 325. AGI, Sevilla. Lo editó Franco (1946, anexo I).

\section{(이)(1)}


Trento. A partir de 1611 cuando Trejo y Sanabria dictó los documentos de su erección y fundación, ya no sólo se mantendría de rentas eclesiásticas, ni su gobierno estaría exclusivamente a cargo del obispo, como hasta entonces lo había estado. El rey lo dotó con rentas, dio poder al gobernador para participar de la elección de colegiales y, además, quedó bajo la administración de la Compañía de Jesús.

A raíz de las solicitudes e informes enviados al Consejo, en 1609 se dictó una cédula real ordenando la creación del seminario. En ella se mandó financiarlo con 2000 pesos de a ocho reales, 650 procedentes de rentas eclesiásticas y 1350 de pensiones, las cuales se cargarían a las encomiendas vacantes; mientras estas quedaban libres ese monto se cubriría con los dos novenos del diezmo pertenecientes al rey. ${ }^{60}$

A continuación, se ordenó a Trejo y Sanabria hacer el seminario con el número de estudiantes que pudiera sustentar aquella renta. El objetivo, decía esta cédula, era que aquellos se criaran "con la virtud y disciplina que conviene para que salgan buenos estudiantes y lenguas necesarias de los indios, y se puedan ordenar de sacerdotes y servir y ocupar en las doctrinas de ellos y administrar los sacramentos". ${ }^{1}$

De acuerdo con la cédula, la administración y cuidado del estudio se daría a uno o dos padres de la Compañía de Jesús; pero mientras este se financiara con rentas reales, la elección de colegiales la harían, de forma conjunta, el obispo y el gobernador. Si no había acuerdo entre ellos, se desempataría con el parecer del preceptor del seminario, es decir, un jesuita. Así, poco quedaría de las características que diferenciaban a los seminarios de otros centros de instrucción, lo cual es aún más patente en los acuerdos celebrados con la orden, donde se dispuso sobre el financiamiento y gobierno.

Ya con la cédula donde se ordenaba la fundación formal, el siguiente paso era convencer a los jesuitas para ir a Santiago del Estero y tomar a su cargo el establecimiento, como lo había ordenado el rey.

Desde la llegada de los padres Angulo y Barzana en noviembre de 1585, en Santiago del Estero sólo habían permanecido uno o dos jesuitas, pues conforme llegaban nuevos, se repartían en el territorio. A partir de 1594, anota Astrain, se establecieron en Santiago y la Asunción, pero allí sólo tenían "la

${ }^{60}$ Dotación de rentas para la fundación de seminario en Tucumán. 25 de julio de 1609. Patronato, 275, R. 88. AGI, Sevilla.

${ }^{61}$ Dotación de rentas para la fundación de seminario en Tucumán. 25 de julio de 1609. Patronato, 275, R. 88. AGI, Sevilla.

\section{(ㅇ)(1) $\$$}


morada que ocupaban para vivir" (Astrain, 1913, vol. IV, pp. 604-643). Mientras tanto, en la ciudad de Córdoba, la orden recibió en 1591 un solar cerca del río y un terreno para huerto, el cual se ocupó de manera definitiva a partir de 1599, con la llegada de los padres Juan Romero y Juan Darío. Luego, cuando en 1604 se ordenó dividir la provincia jesuita del Perú, para dar origen a la del Paraguay y Tucumán, la casa de Córdoba adquirió mayor importancia. De hecho, para 1610 había en ella 24 religiosos, mientras la de Santiago del Estero había sido despoblada por el provincial Diego de Torres (Astrain, 1913, vol. IV, p. 621). ${ }^{62}$ Así, en octubre de 1610 el obispo Trejo requirió al provincial de la orden para que:

el dicho seminario se funde, y en todo se guarde y cumpla lo que su majestad manda. [El obispo] mandaba y mandó se exhorte, requiera y notifique una, dos y tres veces al dicho padre provincial, venga o mande dentro de 40 días, después de la notificación, a poblar en esta ciudad, donde está la iglesia catedral y ha de estar el Colegio Seminario, queriendo tomarle y tenerle y a su cargo. ${ }^{63}$

A continuación, en noviembre de 1611, Trejo estableció un acuerdo con la orden donde se dictaron providencias sobre la forma de financiamiento del seminario, el número de colegiales y su gobierno. ${ }^{64}$ En el acuerdo se estableció que la Compañía de Jesús recibiría 1100 pesos para el sustento de quienes atendieran la enseñanza y el gobierno, pagados "del tercio de los diezmos de la ciudad de Santiago, que solía ser de cuatrocientos a quinientos pesos". Es decir, se invertiría 55\% del presupuesto total del seminario tan sólo en los servicios de los jesuitas. Además, el obispo se obligó a acabar una casa que estaba labrando, con suficiente habitación para los seis colegiales y los jesuitas necesarios, una capilla, dos aulas y las oficinas convenientes. Daría también dos esclavos para servicio y reparo de la casa y mantenimiento de una huerta de recreación; por su parte, el visitador y el gobernador dejarían señalados indios de mita.

Los seminaristas serían seis, vestirían ropas pardas y becas azules - como los del colegio de Santo Toribio de Lima-, y sólo deberían acudir a la

${ }^{62}$ Carta del obispo del Tucumán en respuesta a varias reales cédulas. 4 de noviembre de 1610 (citada en Levillier, 1926, vol. I, pp. 90-94).

${ }_{63}$ El documento fue editado en Grenón (1941, pp. 11-12).

${ }^{64}$ Los documentos del Acuerdo y la Erección en Grenón (1941, pp. 37-39).

\section{(ㅇ)(1) $\$$}


catedral los domingos y fiestas principales. Para su instrucción, la compañía señalaría un maestro de gramática y, a su tiempo, otros más para las cátedras de mayores y casos de conciencia. Se anotó también que los jesuitas podrían admitir otros colegiales, quienes pagarían sus propios alimentos, usarían becas coloradas, y no tendrían obligación alguna de asistir al servicio de la catedral (Grenón, 1941, pp. 37-39). Sobre el gobierno del seminario se acordó que ni el obispo ni la sede vacante podrían intervenir, pues el colegio jesuita tendría la superintendencia y nombraría para el gobierno a un clérigo idóneo.

Es de notar cómo no se tenía pensado dar la superintendencia a uno o dos jesuitas, como había dispuesto el rey, sino a un colegio de la orden, el cual pretendía fundar el obispo en la ciudad. De hecho, al final del acuerdo, Trejo y Sanabria ofreció dotar "al Colegio de la Compañía de Santiago, el cual era deseo suyo muy antiguo, para que con mejor asiento pudiesen perseverar allí los jesuitas, y amparar al seminario". Así, pues, se trataba de establecer dos instituciones distintas: un seminario pagado de bienes eclesiásticos y rentas reales, y un colegio jesuita, el cual sería dotado por Trejo.

Luego del acuerdo, en noviembre de 1612, se haría la escritura de erección del seminario, disponiéndose sobre el perfil de los colegiales, su asistencia a la iglesia, fiestas y procesiones, disciplina, vida interna y hábito, así como sobre el edificio y sus rentas (Grenón, 1941, pp. 12-16). Disposiciones donde es claro cómo el seminario era sólo un instrumento para asentar a los jesuitas en la ciudad.

En la escritura, el obispo ratificó y puntualizó los acuerdos previos. Así, se volvió a referir a la donación de dos casas. La primera, aún en construcción, junto a la catedral, la dio al seminario, y la otra, una "casa bastante y decente", la donó a la Compañía de Jesús, "para lo que los superiores quisieren”. Mientras se terminaba la obra del seminario, en esta última podrían habitar los religiosos, leer y tener algunos colegiales.

Si bien sólo se pudieron reunir 1700 pesos en total, la Compañía de Jesús obtendría los 1100 ya acordado. Los 600 pesos restantes se utilizarían para cuatro seminaristas, pues el dinero no alcanzaba para los seis estipulados en un principio. De esos 600 también debían pagarse los gastos comunes de la casa, el barbero y el maestro de canto. El vestido, los libros y todo lo demás deberían de proveerlo los familiares de los alumnos. Además, si el superintendente nombrado por los jesuitas para encargarse de la casa era un clérigo secular, recibiría para su sustento y por su trabajo dos capellanías de catedral.

El establecimiento del seminario estaba muy lejos de ser una solución para atender la evangelización de la inmensa diócesis del Tucumán, sobre

\section{()(1) $\circledast$}


todo porque, a fin de cuentas, este sólo tendría una cátedra de gramática y cuatro becas.

Según informó Trejo, en 1610 había en toda la diócesis 46 clérigos, quienes atendían doctrinas y curatos. ${ }^{65}$ En ese mismo año, los dominicos tenían un convento en Córdoba con tres o cuatro frailes; los franciscanos tenían seis casas, aunque con pocos religiosos, entre dos y seis en las ciudades de Córdoba, Santiago, Tucumán, Rioja, Talavera y Salta. Igual número tenían los mercedarios, "y aun creo más diminuto", decía el obispo. Es decir, si bien los clérigos habían aumentado, había casi el mismo número de frailes que en 1586, pues, como he señalado, no se había ejecutado la cédula de 1593, donde se ordenó traer religiosos de Lima, ni tampoco se dieron nuevas órdenes al respecto para poblar esos conventos.

A diferencia de las otras órdenes, la corona había favorecido la expansión de la Compañía con gran rapidez. Como señalamos, para 1610 esa orden tenía dos casas: una en Córdoba, con más de 24 religiosos, y otra en la ciudad de Tucumán, con cuatro. Además, luego de haberse creado la provincia del Paraguay y Tucumán se enviaron a ella 45 misioneros procedentes de las provincias de Nápoles, Castilla, Aragón, Toledo, Andalucía, Roma y Milán (Astrain, 1913, vol. IV, pp. 629-230). En consecuencia, poco tiempo después, se crearían residencias en Buenos Aires, Mendoza y Santa Fe, donde se seguirían recibiendo barcadas de religiosos en los años siguientes.

Así, ante el pequeño número de clérigos y el nulo crecimiento de las órdenes mendicantes, Trejo se avocaría a impulsar el arraigo de los jesuitas para favorecer la evangelización del Tucumán. Además, el obispo sentía por la orden una particular admiración y aspiraba a ser reconocido en ella como "fundador".

Desde 1565 la Compañía había tomado medidas para controlar las donaciones hechas a sus colegios. Preocupación de esas disposiciones era que se dotara a los establecimientos de todo lo necesario, para que los padres pudieran vivir sin pedir limosna, incompatible con el estudio. ${ }^{66}$ Se requería, pues, ofrecer un edificio acomodado y la renta suficiente para mantener a los catedráticos y demás personal, sustentar algunos novicios y estudiantes.

${ }^{65}$ Carta del obispo del Tucumán en respuesta a varias reales cédulas. 4 de noviembre de 1610 (citada en Levillier, 1926, vol. I, pp. 90-94). Las doctrinas, dijo el obispo, eran muy pobres, "no hay quien las apetezca; me será fuerza hacerles tan buen agasajo y obras que los obligue a permanecer en ellas y a no dejarlas".

${ }^{66}$ Modus in fundatione collegiorum servandus y De ratione constituendi Collegia (citado en Gómez, 1901, pp. 25-45).

\section{(이요 $\$$}


A quienes daban casa y renta suficiente para mantener un colegio, la orden les declaraba oficialmente como "fundadores", y eran obsequiados con oraciones, misas y otros bienes espirituales, y quienes les favorecían en menor grado, eran llamados "bienhechores", y eran correspondidos con gracias espirituales, aunque sin el carácter oficial y preeminente dado a los primeros (Astrain, 1905, vol. II, pp. 594-595).

Para dar cumplimiento a esos requisitos, y así poder convertirse en fundador del colegio jesuita de Santiago, Trejo dictó, al mes siguiente de la erección del seminario, una escritura de dotación de bienes, donde se comprometió a dar 20000 ducados de Castilla a la orden ${ }^{67}$ También prometió darle toda su hacienda, "así muebles como raíces, libros y todo lo demás que tuviere", al tiempo de su fallecimiento. Además, mientras viviera en el obispado, el obispo le daría su cuarta episcopal de los diezmos de la ciudad de Santiago, y si el rey lo promovía a otra diócesis, le dejaría todos sus bienes muebles y libros, excepto su Pontifical y lo necesario para el camino.

Al año siguiente, Trejo puntualizó la escritura de dotación, dando a la compañía 20 ducados de castilla para que "los padres de ella estén de asiento en la dicha ciudad y puedan hacer casa e iglesia decente y que tengan con qué se sustentar". A cambio, la orden debía recibirle "por fundador del dicho colegio y hacerme decir por toda la Compañía [...] los sufragios acostumbrados".

Así, es claro cómo más que fundar un seminario tridentino, el obispo aspiraba a convertirse en fundador de un colegio jesuita, pues, además del reconocimiento, la orden podría proveer de nuevos ministros a la diócesis y podría hacerse cargo de la evangelización de los indios, como lo había venido haciendo desde su llegada al Tucumán.

Una última muestra de cómo el objetivo prevalente en la actuación de Trejo era la Compañía de Jesús y no el seminario, lo es su testamento, firmado en 1614. Allí señaló que su intención primera había sido siempre fundar un colegio jesuita en la ciudad de Córdoba, para el cual dejaba toda su hacienda, bienes, derechos y acciones habidos y por haber, ${ }^{68}$ donación que debía ser preferida a cualquier otra. Es decir, lo prometido al colegio de Santiago del Estero, el cual debía tener la superintendencia del seminario, sólo se cumpliría cuando tuviera efecto el colegio de Córdoba.

${ }^{67}$ El documento en Grenón (1941, pp. 24-30).

${ }^{68}$ Expediente de la universidad de Córdoba de Tucumán. Buenos Aires, 325. AGI, Sevilla; Franco (1946, anexo I).

\section{(이요 $\$$}


convenimos y fuimos de acuerdo el dicho P. Provincial y yo, de que en caso que yo no pudiese cumplir con las dichas dos fundaciones de este Colegio de Córdoba y el de Santiago, este de Córdoba fuese preferido y antepuesto al de Santiago [...] por ser en mayor bien y más universal de este obispado y de la dicha Compañía y lo que yo siempre había deseado.

A pesar de ello, los jesuitas conservarían la casa de Santiago, y el seminario seguiría recibiendo 3\% de las rentas eclesiásticas y las pensiones sobre los novenos y las encomiendas. Así, en 1613, un año antes de la muerte de Trejo, el provincial de la Compañía de Jesús escribió en las cartas anuas que en Santiago del Estero había dos padres, dos coadjutores y un hermano, quien enseñaba a los alumnos del seminario de Santa Catarina Mártir, el cual "funciona en nuestra casa". ${ }^{69}$

Tres años después, el padre Oñate anotó en las anuas cómo el Colegio de Santiago tenía a su cargo seis colegiales sustentados por el rey, para el servicio de la Iglesia. Además de aquellos, decía Oñate, el colegio jesuita había "aumentado en el número de los nuestros, con la cátedra de moral" y, finalmente, para 1618, aquel mismo padre registró cómo el colegio jesuita de Santiago contenía "en sí un Colegio seminario de estudiantes seglares, que es el de este obispado conforme al concilio Tridentino, y tiene 9 colegiales, no más, y para ellos 1400 pesos de renta" ${ }^{70}$

Como es sabido, aquellos seminaristas pronto serían expulsados del edificio. En 1621 el obispo Cortázar explicó al rey cómo el padre rector había impedido que los colegiales sirvieran a la catedral, argumentando que la mayor parte de las rentas para sostenerlos las daba el rey y, por lo tanto, no tenían obligación de acudir al servicio de la Iglesia, ni el obispo los podía obligar.

Es decir, el rector del colegio de la Compañía alegaba que no se trataba de un seminario tridentino, y algo tenía de razón. De las rentas, $67.5 \%$ la daba la corona, la elección de colegiales la hacía el gobernador y el obispo, el gobierno de los estudiantes lo tenía a su cargo la orden, quien disponía también sobre el estudio y, además, el edificio donde se albergaba a los seminaristas era de la compañía. La casa prometida por Trejo para el seminario nunca se hizo, pues sus bienes fueron donados enteramente al Colegio de Córdoba. ${ }^{71}$

${ }^{69}$ Carta anua de 1613 (citada en Ravignani y Leonhardt, 1927).

${ }^{70}$ Cartas de 1616 y 1618-1619, escrita en febrero de 1620 (citadas en Ravignani y Leonhardt, 1927).

${ }^{71}$ Tantos fueron los pleitos de lo legado por Trejo a ese colegio que, escribió el padre Oñate: "lo que quedará en paz, será de muy poca consideración, y así sólo quedará el señor

\section{()(1) $(3$}


Los pleitos entre los obispos, el Cabildo y los jesuitas continuarían. De hecho, para 1628 los capitulares se negaron a contribuir con el seminario, pues, según dijeron, los colegiales no servían a la catedral y la orden no cumplía con los compromisos adquiridos en la fundación (Grenón, 1941, pp. 45 y 47). Como resultado de las disputas, en 1634 la Compañía de Jesús renunció a la dirección de los seminaristas y, por lo tanto, estos debieron salir de la casa donada por Trejo a los ignacianos y buscar un nuevo local.

\section{CONCLUSIONES}

A diferencia de otros colegios, el seminario de Santiago del Estero no vino a trastocar un orden establecido e intereses creados, pues, prácticamente, fue una institución fundacional de la Iglesia del Tucumán. Por ello, su creación, en torno a 1606, fue bastante sencilla y, de hecho, pasa desapercibida. Mucho más notoria fue su posterior fundación jurídica, pues con la intención de darlo en administración a la Compañía de Jesús, se debieron elaborar documentos legales de erección y dotación.

Tratando de explicar por qué se había dado a los jesuitas la administración de diversos colegios tridentinos en América, Vergara Ciordia (2003, p. 85) anotó que ello podría responder a un intento de aprovechar la sólida infraestructura brindada por la Compañía para sacar adelante sacerdotes diocesanos y seminarios. Si bien ello podría sostenerse de manera general, en el Tucumán no había un interés real por el seminario diseñado en Trento, sino por hacer que los jesuitas se quedaran en la provincia para atender a las necesidades de aquella inmensa diócesis.

Para los años setenta del siglo XVI las primeras órdenes religiosas llegadas a Indias habían disminuido su actividad misional; además, prestaban gran resistencia al control de la corona y mantenían constantes disputas con los obispos, debido a los privilegios con los cuales habían pasado a Indias. Por el contrario, como ha explicado Jessica Ramírez (2014), la Compañía de Jesús, como otras órdenes nuevas o reformadas, fue vista como una vía para ayudar al fortalecimiento del minoritario clero secular. Sobre todo porque se habían dado a conocer como formadores del clero y como coadjutores en las parroquias. Este último punto, señala aquella autora, era fundamental,

obispo por benefactor". Carta de 28 de diciembre de 1614 (citada en Ravignani y Leonhardt, 1927). Véase también Franco (1946, pp. 17-18).

\section{(ㅇ)(1) $(9$}


pues la vía para consolidar una Iglesia sujeta a la corona era mediante el fortalecimiento de la figura episcopal, a lo cual, se pensaba, colaborarían los jesuitas. Debido "al modo de proceder suyo, que principalmente consiste en la predicación, doctrina e institución cristiana, y en ayudar y adoperar a los prelados y otros ministros eclesiásticos, siendo como esto es tan proprio y tan apropósito de lo que conviene en aquellas provincias". ${ }^{72}$

Así, en lugar de aumentar el número de frailes de los conventos mendicantes del Tucumán, los cuales, como vimos, prácticamente no crecieron en el último cuarto del siglo XVI, se decidió apoyar a los jesuitas. Estos prometían ser una mejor opción, no sólo para el prelado sino también para el rey, quien en los años setenta del siglo xvi había aceptado su arraigo en Indias, debido, sobre todo, a las necesidades de expansión y evangelización (véase Santos, 1992).

Por otra parte, el paso del seminario a esa orden tampoco se debió a la falta de una estructura diocesana capaz de sostenerlo ni a la carencia de rentas eclesiásticas, como también supuso Vergara Ciordia (2003, p. 91). Como hemos visto, a partir de 1595-1596 se registró un incremento importante en el diezmo del obispado; luego, se benefició el régimen parroquial, se regularizó la vida capitular y la de la catedral en su conjunto y, a más de ello, el rey dotó de rentas a la institución, con lo cual la transformó profundamente, pues dejo de ser un seminario tridentino, para convertirse en unas becas dentro de un colegio jesuita, las cuales eran pagadas mayoritariamente por el rey.

En 1695, cuando se hizo la confirmación de la encomienda de los pueblos de Soto y Salsacate a don Fernando de Salguero, se apuntó la obligación de "dar y pagar todos los años al colegio seminario de la catedral de esta provincia, tres pesos corrientes" para desempeñar los reales novenos ${ }^{73}$ Luego, cuando se dispusieron los preparativos para trasladar la catedral de Santiago del Estero a la ciudad de Córdoba, se ordenó aplicar a la nueva sede los 8472 pesos que tenían los oficiales reales, de dineros del seminario. ${ }^{74}$ Lo cual hace constar cómo la corona siguió manteniendo a la institución, controló sus finanzas, y sus colegiales debieron seguir siendo electos entre el gobernador y el prelado. Así, aun luego de ser abandonado por los jesuitas, el seminario de Santiago no volvió a ser, al menos durante los siglos XVI y XVII, un colegio como el dispuesto por Trento.

${ }^{72}$ Legajo 41, f. 52. AgmJ, Madrid.

${ }^{73}$ Expediente de confirmación de encomienda. 22 de marzo de 1695. Charcas, 111, N. 8. AGI, Sevilla.

${ }^{74}$ Expediente de traslado de la Catedral de Santiago del Estero, 1678. Charcas, 390. AGI, Sevilla.

\section{(ㄷ)(1) $\$$}




\section{LISTA DE REFERENCIAS}

Altamira, L. R. (1943). El seminario conciliar de Nuestra Señora de Loreto. Colegio mayor de la Universidad de Córdoba (Universitaria, vi). Córdoba: Imprenta de la Universidad.

Astrain, A. (1905). Historia de la Compañía de Jesús en la asistencia de España. Laínez-Borja, 1556-1572 (vol. II). Madrid: Sucesores de Rivadeneyra.

Astrain, A. (1913). Historia de la Compañía de Jesús en la asistencia de España. Aquaviva (segunda parte), 1581-1615 (vol. Iv). Madrid: Administración de Razón y Fe.

Barnadas, J. M. (1995). El seminario conciliar de San Cristóbal de la Plata-Sucre (15951995). Aportación a su historia en el IV centenario de su fundación. Sucre: Archivo-Biblioteca arquidiocesanos "Monseñor Taborga".

Carrillo Cázares, A. (ed.) (2007). Manuscritos del concilio tercero provincial mexicano (1585) [Colección Fuentes] (t. 2, vol. II). Zamora: El Colegio de Michoacán/Universidad Pontificia de México.

Córdoba y Salinas, D. de (1957). Crónica franciscana de las provincias del Perú [Franciscan Historical Classics, 1] (vol. I). Washington: Academy of American Franciscan History.

Doucet, G. G. (1998). Vecinos, moradores, residentes y otros habitantes de tres ciudades tucumanenses en 1608. Genealogía. Revista del Instituto Argentino de Ciencias Genealógicas, 29, 497-542.

El Sacrosanto y Ecumenico Concilio de Trento (1785) [traducido al idioma castellano por Don Ignacio López de Ayala, agrégase el texto latino corregido según la edición auténtica de Roma, publicada en 1564]. Madrid: Imprenta Real.

Franco, J. R. del (1946). Establecimiento y progreso de los primeros estudios superiores en Córdoba, época: años 1609 a 1879. Córdoba: Talleres Gráficos Biffignandi.

Gómez Rodeles, C., Lecina, M., Ortiz, A., Agustí, V., Cervos, F. (eds.) (1901). Monumenta paedagogica societatis Jesu quae primam rationem studiorum anno 1586 editam praecessere. Madrid: Agustini Aurial.

Grenón, P. (1941). Fundaciones. El colegio Seminario de Santa Catalina en Santiago del Estero. Córdoba: Imprenta de la Universidad.

Kitchin, T. (1790). América del Sur que contiene Tierra Firme, Guayana, Nueva Granada, la Amazonia, Brasil, Perú, Paraguay, Chaco, Tucumán, Chile y la Patagonia, con varias adiciones y mejoras..., 1787. En A general atlas, describing the whole universe: being a complete collection of the most approved maps extant... (pp. 34-35). Londres: Robert Sayer.

\section{()(1) $\$$}


Levillier, R. (ed.) (1920). Gobernación del Tucumán. Papeles de gobernadores en el siglo XVI. Documentos del Archivo de Indias [Publicaciones históricas de la Biblioteca del Congreso Argentino] (1a parte, vol. I). Madrid: Juan Pueyo.

Levillier, R. (ed.) (1924). Gobernantes del Perú. Cartas y papeles, siglo XVI. Documentos del Archivo de Indias [Publicaciones históricas de la Biblioteca del Congreso Argentino] (vol. v). Madrid: Juan Pueyo.

Levillier, R. (ed.) (1926). Papeles eclesiásticos del Tucumán. Documentos originales del Archivo de Indias [Publicaciones históricas de la Biblioteca del Congreso Argentino] (vol. I). Madrid: Imprenta de Juan Pueyo.

Lozano, P. (1754). Historia de la Compañía de Jesús en la provincia del Paraguay, escrita por el padre Pedro Lozano de la misma Compañía (vol. 1). Madrid: Imprenta de la viuda de Manuel Fernández.

Matienzo, J. de (1910). Gobierno del Perú. Obra escrita en el siglo XVI por el licenciado don Juan Matienzo, oidor de la Real Audiencia de Charcas [Facultad de Filosofía y Letras, Sección de Historia]. Buenos Aires: Compañía Sud-Americana de Billetes de Banco.

Muriel, D. (1776). Fasti Novi Orbis et ordinationum apostolicarum ad Indias pertinentium breviarium cum adnotationibus. Opera D. Cyriaci Morelli presbyteri, olim in universitate Neo-Cordubensi in tucumania professoris. Venecia: Antonio Zatta.

Palomeque, S. (2005). Santiago del Estero y el Tucumán durante los siglos XVI y XVII. La destrucción de las tierras bajas en aras de la conquista de las tierras altas. En S. Palomeque (coord.), I. Castro Olañeta, S. Tell, C. Crouzeilles, y E. Tedesco, Actas del cabildo eclesiástico. Obispado del Tucumán con sede en Santiago del Estero, 1592-1667 (pp. 45-75). Córdoba: CIFFYH-Universidad Nacional de Córdoba/Ferreyra Editor.

Palomeque, S. (coord.), Castro Olañeta, I., Tell, S., Crouzeilles, C. y Tedesco, E. (2005). Actas del cabildo eclesiástico. Obispado del Tucumán con sede en Santiago del Estero, 1592-1667. Córdoba: CiffyH-Universidad Nacional de Córdoba/Ferreyra Editor.

Pastells, P. (ed.) (1912). Historia de la Compañía de Jesús en la provincia del Paraguay (Argentina, Paraguay, Uruguay, Perú, Bolivia y Brasil) según los documentos originales del Archivo General de Indias, extractados y anotados por el R. P. Pablo Pastells (vol. I). Madrid: Librería General de Victoriano Suárez.

Pérez Puente, L. (2010a). El concierto imposible: los concilios provinciales en la disputa por las parroquias indígenas (México, 1555-1647) [La Real Universidad de México, Estudios y Textos, 21]. México: IIsue-unAm.

Pérez Puente, L. (2010b). Un seminario conciliar entre dos iglesias. Quito 1565-1583. En J. Correa (coord.), Facultades y Grados. X Congreso Internacional de Historia de las

\section{(ㅇ)(1) $(3$}


universidades hispánicas. Valencia, noviembre de 2007 (vol. II, pp. 219-242). Valencia: Universidad de Valencia.

Pérez Puente, L. (2012). Un colegio en tiempos de guerra. El seminario tridentino de Santiago de 1585 en la historiografía chilena del siglo xIX. En M. Peset y J. Correa (coords.), Matrícula y lecciones. XI Congreso internacional sobre historia de las universidades hispánicas (vol. 1, pp. 177-196). Valencia: Universidad de Valencia.

Ramírez Méndez, J. (2014). Los carmelitas descalzos en la Nueva España. Del activismo misional al apostolado urbano, 1585-1614. México: INAH.

Ravignani, E. y Leonhardt, C. (eds.) (1927). Cartas anuas de la provincia del Paraguay, Chile y Tucumán, de la Compañía de Jesús [Documentos para la Historia de Argentina, 19-20]. Buenos Aires: Casa Jacobo Peuser/Universidad de Buenos Aires.

Ribadeneyra, P. de (1595). Las obras del P. Pedro de Ribadeneyra de la Compañía de Jesús: ahora de nuevo revistas y acrecentadas. Madrid: Viuda de Pedro Madrigal.

Santos Hernández, Á. (1992). Los jesuitas en América. Madrid: MAprre.

Toscano, J. (1907). El primitivo obispado del Tucumán y la iglesia de Salta [Estudios Históricos] (vol. I). Buenos Aires: Imprenta de M. Biedma e hijo.

Vergara Ciordia, J. (2003). Historia y pedagogía del seminario conciliar en Hispanoamérica, 1563-1800, Madrid: Dykinson.

\section{OTRAS FUENTES}

Archivos

AgI Archivo General de Indias, Sevilla.

AgmJ Archivo General del Ministerio de Justicia, Madrid. 